\title{
Increased Epicardial Fat Volume Quantified by 64-Multidetector Computed Tomography is Associated With Coronary Atherosclerosis and Totally Occlusive Lesions
}

\author{
Koji Ueno, MD; Toshihisa Anzai, MD; Masahiro Jinzaki, MD*; Minoru Yamada, MS*; \\ Yusuke Jo, MD; Yuichiro Maekawa, MD; Akio Kawamura, MD; \\ Tsutomu Yoshikawa, MD; Yutaka Tanami, MD*; Kozo Sato, MD*; \\ Sachio Kuribayashi, MD*; Satoshi Ogawa, MD
}

\begin{abstract}
Background: The relationship between the epicardial fat volume measured by 64-slice multidetector computed tomography (MDCT) and the extension and severity of coronary atherosclerosis was investigated.

Methods and Results: Both MDCT and conventional coronary angiography (CAG) were performed in 71 consecutive patients who presented with effort angina. The volume of epicardial adipose tissue (EAT) was measured by MDCT. The severity of coronary atherosclerosis was assessed by evaluating the extension of coronary plaques in 790 segments using MDCT data, and the percentage diameter stenosis in 995 segments using CAG data. The estimated volume of EAT indexed by body surface area was defined as VEAT. Increased VEAT was associated with advanced age, male sex, degree of metabolic alterations, a history of acute coronary syndrome (ACS) and the presence of total occlusions, and showed positive correlation with the stenosis score $(\mathrm{r}=0.28$, $\mathrm{P}=0.02)$ and the atheromatosis score $(\mathrm{r}=0.67, \mathrm{P}<0.0001)$ of the coronary arteries. Multiple logistic regression analysis revealed an increased VEAT $\left(\geq 50 \mathrm{~cm}^{3} / \mathrm{m}^{2}\right)$ to be the strongest independent determinant of the presence of total occlusions (odds ratio 4.64, $\mathrm{P}=0.02$ ).

Conclusions: VEAT correlates with the degree of metabolic alterations and coronary atheromatosis. Excessive accumulation of EAT might contribute to the development of ACS and coronary total occlusions. (Circ J 2009; 73: 1927-1933)
\end{abstract}

Key Words: Acute coronary syndrome; Atherosclerosis; Computed tomography; Coronary artery diseases; Occlusion

I $\mathrm{t}$ is widely recognized that accumulation of abdominal visceral fat is strongly related to the development of coronary artery disease (CAD). ${ }^{1-6}$ Epicardial adipose tissue (EAT) is the actual visceral fat of the heart deposited under the visceral layer of the pericardium and has the same origin as abdominal visceral fat. Pathological investigations revealed EAT and the adventitia of coronary arteries or myocardium to be contiguous, with no intervening structures. ${ }^{7}$ The accumulation of EAT shows a good correlation with the volume of abdominal visceral fat and EAT is also known to be a rich source of free fatty acids and a number of bioactive molecules and inflammatory cytokines ${ }^{8-11}$ Some reports have suggested a crucial role of EAT in the development of CAD through changes in adipokine expressions in EAT, which promote pro-inflammatory characteristics, thereby possibly facilitating the progression of coronary atherosclerosis. ${ }^{9-11}$ In fact, de Vos et al have reported that peri-coronary EAT thickness is strongly related to vascular risk factors and coronary calcification in post-menopausal women. ${ }^{12}$
A recent study demonstrated that 64-slice multidetectorrow computed tomography (MDCT) is suitable for volumetric quantification of EAT with higher reproducibility than measurements of EAT thickness by echocardiography, and that excessive accumulation of EAT was associated with obesity and metabolic syndrome. ${ }^{13}$ MDCT provides noteworthy information about coronary arteries including not only the presence and degree of stenotic lesions but also of subclinical atherosclerotic plaques. ${ }^{14-19}$ MDCT can identify atherosclerotic plaques, in vessels with only minimal angiographic disease, with high sensitivity and moderate specificity as compared with intravascular ultrasound (IVUS). Moreover, MDCT can detect significant atherosclerotic plaques in vessels with signs of positive remodeling, which tend to be underestimated by conventional coronary angiography (CAG). ${ }^{20,21}$ We sought to determine the relationship between the epicardial fat volume and the severity and extent of atherosclerosis of the whole coronary tree using CAG and MDCT in patients presenting with a possible diagnosis of stable effort angina.

(Received April 15, 2009; revised manuscript received May 28, 2009; accepted June 14, 2009; released online August 19, 2009)

Division of Cardiology, Department of Medicine, *Department of Diagnostic Radiology, Keio University School of Medicine, Tokyo, Japan

Mailing address: Toshihisa Anzai, MD, Division of Cardiology, Department of Medicine, Keio University School of Medicine, 35 Shinanomachi, Shinjuku-ku, Tokyo 160-8582, Japan. E-mail: anzai@cpnet.med.keio.ac.jp

All rights are reserved to the Japanese Circulation Society. For permissions, please e-mail: cj@j-circ.or.jp 

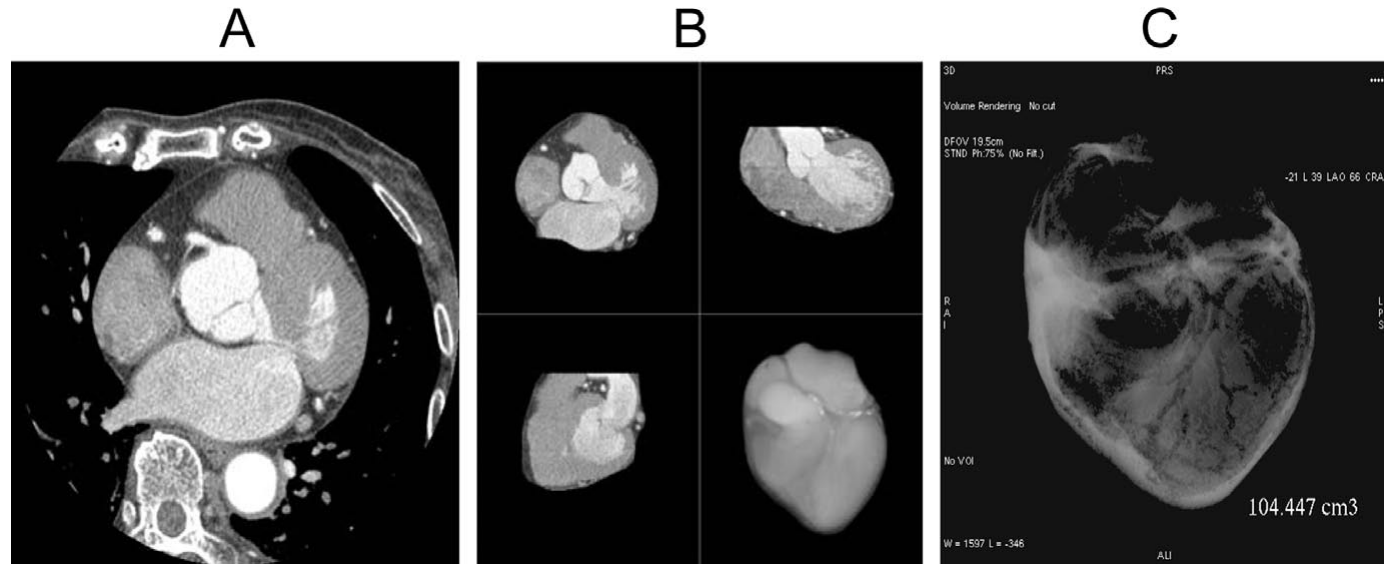

Figure 1. Quantification of EAT by 64-MDCT. (A) Volume data acquisition by 64-MDCT. (B) Segmentation of the epicardium by manual tracing. (C) Quantification of EAT by calculating the volume showing a certain CT density. EAT, epicardial adipose tissue; MDCT, multidetector computed tomography.

\section{Methods}

\section{Study Population}

Both MDCT and CAG were performed in 125 patients presenting with a possible diagnosis of stable effort angina between February 2005 and April 2007 in our institution. Patients presenting with acute chest pain, which was suggestive of acute coronary syndrome (ACS) were not included. MDCT was operated within 2 months prior to CAG. Patients who had the history of an open-heart surgery (18 patients) or coronary stenting (36 patients) were excluded. Finally, 71 patients (36-84 years, median 66 years, 16 female patients) formed the study cohort. The study protocol was in agreement with the guidelines of the Ethics Committee of our institution and was approved by the institutional review board.

\section{Study Protocol}

We measured the volume of EAT and evaluated the relationship with patients' metabolic background and the severity and extension of coronary atherosclerosis. The traditional risk factors for $\mathrm{CAD}$, including the presence of hypertension, diabetes mellitus, a high serum concentration of low-density lipoprotein-cholesterol (LDL-C), smoking and a family history of CAD were obtained from medical records. Metabolic risk factors based on the criteria suggested by the National Cholesterol Education Program (NCEP-ATP III) were also obtained from medical records. It includes mild hypertension, high fasting plasma glucose (FPG), low-serum concentration of high-density lipoprotein-cholesterol (HDL-C), and high serum triglyceride (TG) concentration. Dyslipidemia is identified as being present if the patient is on cholesterol-lowering therapy or has low HDL-C and/or high TGs. In the present study, waist circumstance was not obtained.

CT imaging was performed with a 64-MDCT scanner (LightSpeed VCT, GE Healthcare, Milwaukee, WI, USA). The contrast agent (Iohexol $350 \mathrm{~g} / \mathrm{cm}^{3}$; Omnipaque, DaiichiSankyo, Tokyo, Japan) was injected intravenously at a rate of $3.5-5.0 \mathrm{ml} / \mathrm{s}$ dependent on body weight. Images were acquired with a $64 \times 0.625-\mathrm{mm}$ slice collimation, a gantry rotation time of $350 \mathrm{~ms}$, a tube voltage of $120 \mathrm{kV}$, and an effective tube current of 500-800 mA using ECG-correlated tube current modulation. Images were reconstructed at approximately $75 \%$ of the cardiac cycle in the mid-diastolic phase. Sublingual nitroglycerin $(5 \mathrm{mg})$ was administered for all patients just before scanning. Beta-adrenergic antagonist (metoprolol tartrate $20 \mathrm{mg}$ ) was orally administered $30 \mathrm{~min}$ before a scan only for patients who showed a rapid heart rate $(\geq 70$ beats $/ \mathrm{min})$. The heart rate control $(<70$ beats $/ \mathrm{min})$ was achieved in all patients at the time of the scan.

A novel method of quantifying EAT is shown in Figure 1. First, axial source images were transferred to an office workstation (Advantage Workstation ver. 4.2, GE Healthcare). Second, the volume around the heart was extracted by a precise manual trace of the visceral layer of the pericardium (epicardium) for whole heart. Third, a 3-dimensional image of the heart was constructed, and EAT was quantified by calculating the volume of a certain CT density within the epicardium showing $-200 \leq \mathrm{CT}$ attenuation $\leq-50 \mathrm{HU}$, which is recognized as the density of adipose tissue. The volume of EAT was divided by body surface area and defined as the indexed volume of EAT, that is, as VEAT.

CAG was performed using standard techniques. Total occlusion was defined as a lesion with an abrupt vessel cut-off (100\% angiographic diameter narrowing) and Thrombolysis In Myocardial Infarction trial grade 0 .

\section{Data Acquisition by CAG and MDCT Coronary Angiography}

The presence and severity of CAD were assessed by 3 different scoring systems, as follows:

a. Vessel Score The observers analyzed CAG data focusing on the number of vessels with significant stenosis $(>50 \%$ reduction of lumen diameter compared with the reference diameter) among the 3 major coronary arteries.

b. Stenosis Score Visual estimations of CAG data were made in 15 proximal segments defined by the American Heart Association for proportional reductions in lumen diameter, and a modified Gensini score was assigned to all segments as previously described. ${ }^{22}$ The stenosis score for each patient was obtained by dividing the sum of all segmental scores by the number of evaluated coronary segments. Segments located distal to a total occlusion or distal to a significant stenosis, in the absence of sufficient poststenotic contrast filling, were not evaluated, nor were segments of a hypoplastic coronary artery. ${ }^{23}$ 
c. Atheromatosis Score We used the scoring system previously described by Hamsten et al for the quantification of coronary atheromatosis (Table 1). ${ }^{23}$ Although this scoring system originally used calculations based on CAG data for evaluating the extension and size of coronary plaques, we used CPR, stretched CPR and cross-sectional images obtained from MDCT. This is because of the prominent ability of MDCT to clearly visualize the characteristics of vessel walls. Atheromatous plaque was defined as an abnormal mass within the artery wall, clearly distinguishable from EAT and the coronary lumen. The atheromatosis score for each patient was obtained by dividing the sum of all segmental scores by the number of evaluated coronary segments, as with the stenosis score.

\section{Statistical Analysis}

Continuous data were expressed as mean values \pm SD. The 2 groups were compared using the unpaired t-test or nonparametric means test for continuous variables. Categorical variables were reported as a number and a percentage and compared between groups using the Chi-squared test (with Yates' continuity correction). If one of the cells had an expected count of less than 5, we used Fisher's exact test instead of the Chi-squared test to obtain $\mathrm{P}$ values for categorical variables. Multiple logistic regression analysis was used to assess the effects of various factors on the presence of total occlusions of coronary arteries. Five variables, consisting of those with $\mathrm{P}$ values $<0.10$ by univariate analysis, were further assessed by multiple logistic regression analysis. To determine cut-off points of VEAT as predictors of the presence of total occlusions, receiver operating characteristics curve analyses were performed. All statistical analyses were performed using SPSS 16.0 for Windows (SPSS Inc, Chicago, IL, USA). Statistical significance was defined as a $\mathrm{P}$ value of $<0.05$.

\section{Results}

\section{Patient Backgrounds and VEAT}

For the entire study population, proportions of patients with hypertension, diabetes mellitus and high LDL-C were 55\%, $39 \%$, and $73 \%$, respectively. Patients with metabolic risk factors, including mild hypertension, high FPG, low
Table 1. Scoring System for Coronary Atheromatosis

\begin{tabular}{lc}
\hline & Score \\
\hline Extension & 0 \\
Normal vessel wall & 1 \\
1-2 plaques & 2 \\
2 plaques located in one or several groups & \\
$\quad$ with intervening normal vessel wall portion & 3 \\
$>2$ plaques producing continuous vessel wall irregularities & \\
Mean plaque size & 1 \\
$\quad$ Slight indentation (<10\% reduction of the vessel diameter) & 1 \\
$\quad$ Intermediate size indentation & 2 \\
$\quad$ (10-25\% reduction of the vessel diameter) & 3 \\
\hline Large plaque $(>25 \%$ reduction of the vessel diameter) & \\
\hline
\end{tabular}

Atheromatous plaques in each segment were given one score for extension and another for mean plaque size. The scores for extension and plaque size were then multiplied to produce a segmental atheromatosis score (0-9). The atheromatosis score for each patient was obtained by dividing the sum of all segmental scores by the number of evaluated coronary segments.

HDL-C, high TG and dyslipidemia, accounted for $61 \%$, $44 \%, 21 \%, 25 \%$ and $65 \%$, respectively. Thirty-five patients (49\%) had a history of ACS. Coronary total occlusions were observed in 19 patients (27\%). The mean VEAT quantified by 64-MDCT in the whole study population was $47.6 \pm 14.8 \mathrm{~cm}^{3} / \mathrm{m}^{2}\left(17.0-85.2\right.$, median $\left.47.1 \mathrm{~cm}^{3} / \mathrm{m}^{2}\right)$.

VEAT values were compared between groups with (vs without) various clinical background factors (Table 2). VEAT was significantly greater in patients with advanced age, male sex, obesity, hypertension, diabetes mellitus, high LDL-C, mild hypertension, high FPG, low HDL-C or a history of ACS and coronary total occlusions. Moreover, VEAT correlated positively with the number of metabolic risk factors, including mild hypertension, high FPG, low HDL-C and high TG, with statistical significance (Figure 2). VEAT in patients with 0 (12 patients), 1 (22 patients), 2 (24 patients), 3 (9 patients), and 4 (4 patients) metabolic risk factors was $34.0 \pm 9.1,43.7 \pm 11.6,49.8 \pm 11.7,58.0 \pm 16.1$, and $72.9 \pm 5.1 \mathrm{~cm}^{3} / \mathrm{m}^{2}$, respectively.

\section{Correlations Between the Severity of CAD and VEAT}

a. Vessel Score We examined the correlations between VEAT and vessel score. VEAT was $41.3 \pm 11.7 \mathrm{~cm}^{3} / \mathrm{m}^{2}$ in

Table 2. Patient Background Factors and VEAT

\begin{tabular}{|c|c|c|c|}
\hline & \multicolumn{2}{|c|}{ VEAT $\left(\mathrm{cm}^{3} / \mathrm{m}^{2}\right)$} & \multirow{2}{*}{$\mathrm{P}$ value } \\
\hline & Present & Absent & \\
\hline Age $\geq 70$ years & $52.0 \pm 15.8(27)$ & $44.9 \pm 13.6(44)$ & 0.049 \\
\hline Male & $49.5 \pm 15.0(55)$ & $41.0 \pm 12.3(16)$ & 0.04 \\
\hline $\mathrm{BMI} \geq 25 \mathrm{~kg} / \mathrm{m}^{2}$ & $53.5 \pm 13.1(29)$ & $43.5 \pm 14.6(42)$ & 0.004 \\
\hline Hypertension & $52.8 \pm 13.6(39)$ & $41.3 \pm 13.8(32)$ & 0.0008 \\
\hline Diabetes mellitus & $53.3 \pm 12.8(28)$ & $43.9 \pm 14.9(43)$ & 0.008 \\
\hline LDL-C $\geq 160 \mathrm{mg} / \mathrm{dl}$ & $49.7 \pm 15.3(52)$ & $41.8 \pm 11.6(19)$ & 0.04 \\
\hline Current smoking & $46.6 \pm 16.3(22)$ & $48.0 \pm 14.2(49)$ & 0.72 \\
\hline Family history of CAD & $44.8 \pm 12.7(13)$ & $48.2 \pm 15.2(58)$ & 0.45 \\
\hline $\mathrm{FPG} \geq 110 \mathrm{mg} / \mathrm{dl}$ & $53.0 \pm 16.7(31)$ & $43.4 \pm 11.7(40)$ & 0.006 \\
\hline HDL-C $<40 \mathrm{mg} / \mathrm{dl}$ (male),$<50 \mathrm{mg} / \mathrm{dl}$ (female) & $54.4 \pm 14.8(17)$ & $45.4 \pm 14.2(54)$ & 0.03 \\
\hline $\mathrm{TG} \geq 150 \mathrm{mg} / \mathrm{dl}$ & $50.9 \pm 14.4(18)$ & $46.4 \pm 14.9(53)$ & 0.27 \\
\hline Dyslipidemia & $50.1 \pm 14.3(46)$ & $43.0 \pm 14.7(25)$ & 0.052 \\
\hline History of ACS & $52.9 \pm 15.2(35)$ & $42.4 \pm 12.5(36)$ & 0.002 \\
\hline Coronary total occlusions & $57.6 \pm 13.4(19)$ & $43.9 \pm 13.6(52)$ & 0.0003 \\
\hline
\end{tabular}

Data are shown as mean \pm SD (number of patients).

VEAT, the indexed volume of epicardial adipose tissue; BMI, body mass index; LDL-C, low-density lipoprotein-cholesterol; CAD, coronary artery disease; FPG, fasting plasma glucose; HDL-C, high-density lipoprotein-cholesterol; TG, triglyceride; ACS, acute coronary syndrome. 


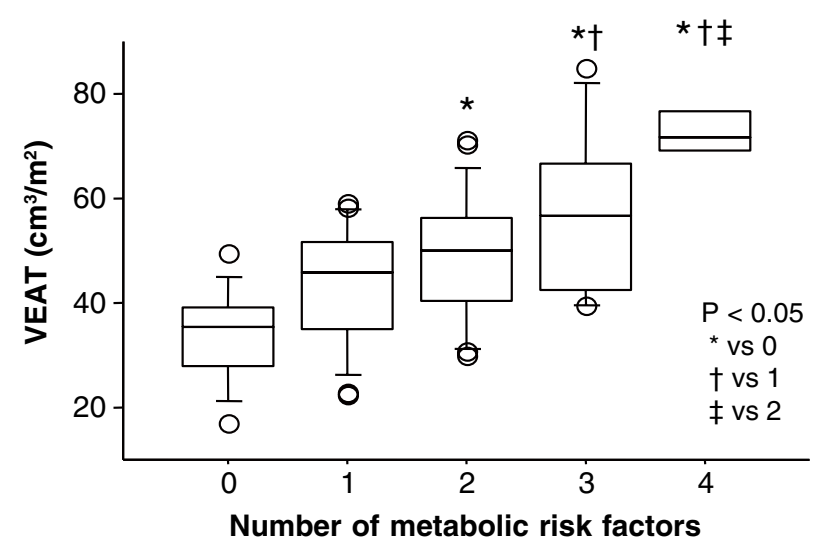

Figure 2. Number of metabolic risk factors and VEAT. Greater VEAT was associated with an increased number of metabolic risk factors. ${ }^{*} \mathrm{P}<0.05$ as compared with no risk factors; ${ }^{\dagger} \mathrm{P}<0.05$ as compared with a single risk factor; ${ }^{\mathrm{P}} \mathrm{P}<0.05$ as compared with 2 risk factors. VEAT, the indexed volume of epicardial adipose tissue.

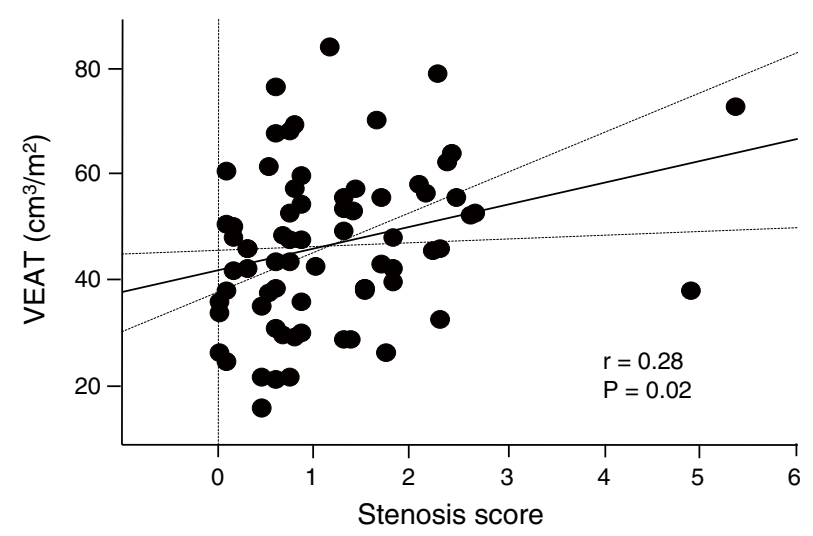

Figure 3. Relationship between the stenosis score and VEAT. VEAT showed a roughly positive correlation with the stenosis score $(\mathrm{r}=0.28$, $\mathrm{P}=0.02)$. VEAT, the indexed volume of epicardial adipose tissue.

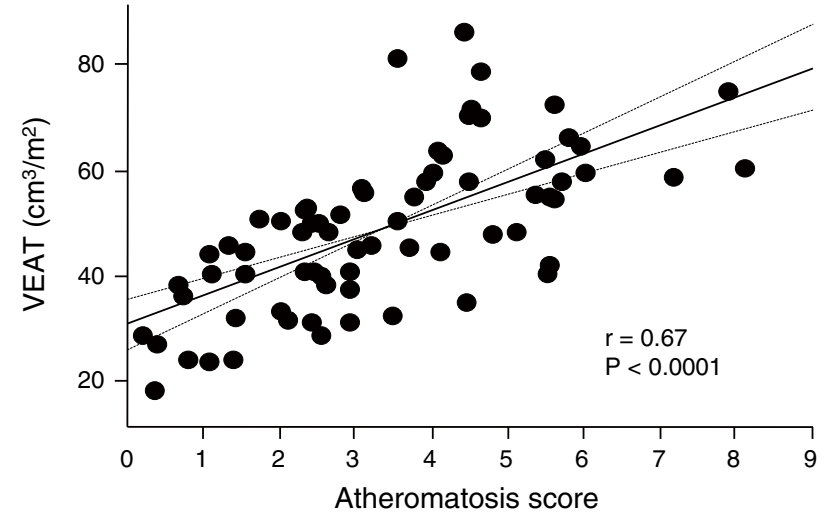

Figure 4. Relationship between the atheromatosis score and VEAT. There was a close positive correlation between the atheromatosis score and VEAT $(r=0.67, \mathrm{P}<0.0001)$. VEAT, the indexed volume of epicardial adipose tissue.

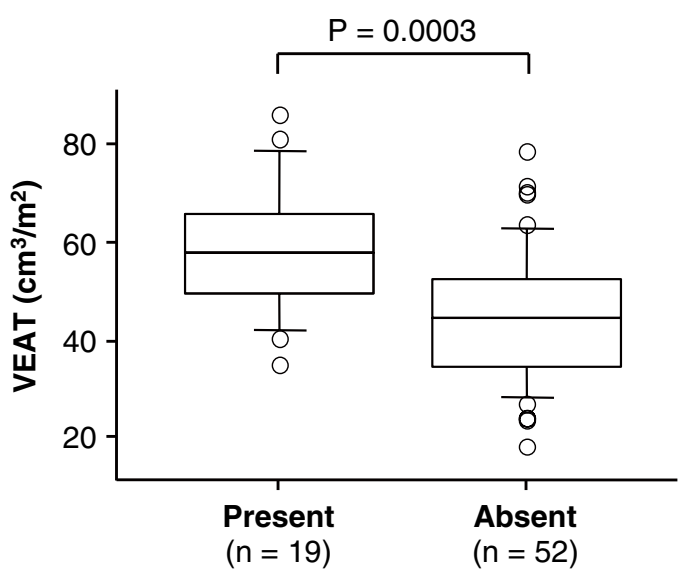

Coronary total occlusions

Figure 5. Presence of coronary total occlusions and VEAT. Patients with coronary total occlusions showed significantly greater VEAT than those without total occlusions. VEAT, the indexed volume of epicardial adipose tissue.

Table 3. Univariate and Multivariate Logistic Regression Analysis for the Presence of Total Occlusions of Coronary Arteries

\begin{tabular}{lcccc}
\hline & \multirow{2}{*}{ Univariate P value } & \multicolumn{3}{c}{ Multivariate analysis } \\
\cline { 3 - 5 } & & OR & 95\%CI & P value \\
\hline VEAT $\geq 50 \mathrm{~cm}^{3} / \mathrm{m}^{2}$ & 0.0006 & 4.64 & $1.21-17.72$ & 0.02 \\
$\mathrm{BMI} \geq 25 \mathrm{~kg} / \mathrm{m}^{2}$ & 0.004 & 4.49 & $1.10-18.34$ & 0.04 \\
$\mathrm{Age} \geq 70$ years & 0.04 & 2.91 & $0.76-11.14$ & 0.12 \\
Male & 0.04 & 2.67 & $0.26-27.75$ & 0.25 \\
Dyslipidemia & 0.04 & 2.05 & $0.43-9.88$ & 0.37 \\
\hline
\end{tabular}

Multiple logistic regression analysis revealed VEAT $\geq 50 \mathrm{~cm}^{3} / \mathrm{m}^{2}$ to be the strongest independent determinant of the presence of coronary total occlusions among variables, which showed statistical significance in univariate analysis.

OR, odds ratio; $\mathrm{CI}$, confidence interval. Other abbreviations see in Table 1.

patients without significant stenosis ( 0 vessel disease, $n=9$ ), $48.5 \pm 17.4 \mathrm{~cm}^{3} / \mathrm{m}^{2}$ in those with single vessel disease $(\mathrm{n}=$ 21), $50.2 \pm 16.2 \mathrm{~cm}^{3} / \mathrm{m}^{2}$ in 2 vessel disease $(\mathrm{n}=17)$ and $47.3 \pm$ $12.2 \mathrm{~cm}^{3} / \mathrm{m}^{2}$ in those with triple-vessel disease $(\mathrm{n}=24)$, and there were no significant differences in VEAT among these groups. Furthermore, there were no significant differences in VEAT between patients with and without multi-vessel disease $\left(48.5 \pm 13.9\right.$ vs $\left.46.3 \pm 16.1 \mathrm{~cm}^{3} / \mathrm{m}^{2}, \mathrm{P}=0.54\right)$, or with and without triple-vessel disease $(47.3 \pm 12.2$ vs $47.7 \pm$ $16.1 \mathrm{~cm}^{3} / \mathrm{m}^{2}, \mathrm{P}=0.92$ ).

b. Stenosis Score As shown in Figure 3, VEAT showed a roughly positive correlation with the stenosis score $(\mathrm{r}=0.28, \mathrm{P}=0.02)$. Patients with a VEAT $\geq 50 \mathrm{~cm}^{3} / \mathrm{m}^{2}$

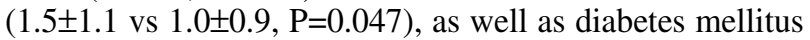
$(1.5 \pm 1.2$ vs $0.9 \pm 0.8, \mathrm{P}=0.01)$ and dyslipidemia $(1.4 \pm 1.1 \mathrm{vs}$ $0.8 \pm 0.7, \mathrm{P}=0.03)$, showed significantly higher stenosis 
scores than those with none of these risk factors.

c. Atheromatosis Score VEAT showed a close positive correlation with the atheromatosis score $(\mathrm{r}=0.67, \mathrm{P}<$ 0.0001 ; Figure 4). Patients with a VEAT $\geq 50 \mathrm{~cm}^{3} / \mathrm{m}^{2}(4.8 \pm$ 1.5 vs $2.4 \pm 1.4, \mathrm{P}<0.0001)$, as well as age $\geq 70$ years $(4.0 \pm 1.7$ vs $3.0 \pm 1.8, \mathrm{P}=0.02)$, male sex $(3.7 \pm 1.9$ vs $2.4 \pm 1.3, \mathrm{P}=0.01)$, hypertension $(3.9 \pm 1.5$ vs $2.7 \pm 2.0, \quad \mathrm{P}=0.007)$, diabetes mellitus (4.2 \pm 1.4 vs $2.8 \pm 1.9, \mathrm{P}=0.002)$ and dyslipidemia (3.7 \pm 1.7 vs $2.8 \pm 2.0, \mathrm{P}=0.04$ ), showed significantly higher atheromatosis scores than those without these risk factors.

\section{ACS, Total Occlusions and VEAT}

Patients with a history of ACS showed significantly larger VEAT than those with no ACS history (52.9 \pm 15.2 vs $42.4 \pm$ $12.5 \mathrm{~cm}^{3} / \mathrm{m}^{2}, \mathrm{P}=0.002$ ). Patients with coronary total occlusions had a larger VEAT than those without coronary total occlusions $\left(57.6 \pm 13.4\right.$ vs $43.9 \pm 13.6 \mathrm{~cm}^{3} / \mathrm{m}^{2}, \mathrm{P}=0.0003$, Figure 5). In patients with a history of ACS, the presence of total occlusions was associated with significantly greater VEAT $\left(57.6 \pm 13.4\right.$ vs $\left.47.3 \pm 15.6 \mathrm{~cm}^{3} / \mathrm{m}^{2}, \mathrm{P}=0.043\right)$. In univariate analysis, an age $\geq 70$ years, male sex, BMI $\geq 25 \mathrm{~kg} / \mathrm{m}^{2}$, dyslipidemia and VEAT $\geq 50 \mathrm{~cm}^{3} / \mathrm{m}^{2}$ were significant determinants of coronary total occlusions. Among those variables, multiple logistic regression analysis revealed a VEAT $\geq 50 \mathrm{~cm}^{3} / \mathrm{m}^{2}$ to be the strongest independent determinant of the presence of coronary total occlusions (odds ratio 4.64, $95 \%$ confidence interval 1.21-17.72, $\mathrm{P}=0.02$, Table 3).

\section{Discussion}

The major findings of the present study were as follows. First, VEAT was greater in patients with advanced age, male sex, obesity, hypertension, diabetes mellitus, metabolic risk factors and a history of ACS and total occlusions. Second, VEAT correlated positively with the number of metabolic risk factors. Third, VEAT correlated with the severity of CAD, especially atheromatosis of the coronary artery. Finally, a VEAT $\geq 50 \mathrm{~cm}^{3} / \mathrm{m}^{2}$ was the strongest independent determinant of coronary total occlusions.

VEAT was significantly greater in patients with proatherosclerotic risk factors. This finding indicates volumetric increases in EAT to be brought about by pro-atherosclerotic environments, just as is the case with abdominal visceral adipose tissues, and could reflect systemic atherosclerosis and the risk of CAD. $8,24,25$ The positive correlation between VEAT and the number of metabolic alterations suggests that VEAT might be a valuable quantitative marker of metabolic impairments and systemic atherosclerosis, and provides us with a clue to risk stratification for CAD. ${ }^{25}$

Expanded EAT might have strong influences as local adipose tissue and might directly affect the pathophysiology of coronary atherosclerosis. ${ }^{26}$ The present study demonstrated that patients with a history of ACS had significantly larger VEAT than those without such a history. Although the conventional scoring system showed a mild correlation with VEAT, the evaluation of CAD severity by coronary atheromatosis with 64-MDCT indicated a much closer correlation between VEAT and the severity of CAD. Previous studies have shown that the composition and vulnerability of plaque rather than the severity of stenosis is important for the development of the thrombus-mediated ACS. ${ }^{27}$ The significant correlation between VEAT and the history of ACS, but not the diseased vessel number, might suggest the possible contribution of epicaridial fat to the plaque composition and vulnerability. Atherosclerotic plaques are developed in individuals with pro-atherosclerotic background factors, and could be the basis of ACS followed by its own rupture or erosion. ${ }^{6,28}$ As plaque composition and plaque burden is suggested to be important prognostic parameters of adverse coronary events, the non-invasive evaluation of atherosclerosis might be useful for risk stratification. ${ }^{20,29}$ Despite its pathophysiological importance, IVUS has been the only modality used to date for evaluating atherosclerotic plaques. However, IVUS is invasive and not suitable for simultaneous assessment of overall coronary plaques. MDCT can examine plaques involving the entire coronary artery safely and rapidly with acceptable sensitivity and specificity. ${ }^{20,29}$ We reported a strong positive correlation between the quantity of EAT and coronary atheromatosis, and suggested that VEAT might be a useful quantitative parameter for prediction of adverse coronary events. In addition, VEAT can be assessed by ECG-gated non-enhanced cardiac CT. Such a method could be applied to the coronary risk screening in future.

Totally occlusive lesions are known to originate from ACS, which is a sudden occlusion caused by bi-directional thrombus formation following the rupture of atherosclerotic plaques with increased instability. ${ }^{30}$ The balance between prothrombotic and fibrinolytic mechanisms prevailing in that particular region determines whether the lesions become totally occlusive or not. ${ }^{31,32}$ Similar to systemic atherosclerosis, modulation of inflammation and coagulation has an important role in the occurrence of ACS and the formation of totally occlusive lesions. 6,33 Upregulation of inflammatory adipokines, downregulation of anti-inflammatory adipokines and increased infiltration of inflammatory cells were observed in EAT of patients with CAD. ${ }^{9-11}$ These findings suggest that atherosclerotic plaques in patients with large amounts of EAT contain abundant pro-thrombotic and pro-inflammatory particles, and is thus susceptible to plaque rupture and thrombus formation. Moreover, an activated coagulation system stimulates inflammatory responses and creates a positive feedback loop. In the present study, patients with total occlusions showed significantly larger VEAT than those without such total occlusions, among patients with a history of ACS. The predominance of pro-thrombotic over proinflammatory activity in patients with increased VEAT might defeat spontaneous thrombolysis and fibrinolysis, and facilitate the formation of total occlusions. $6,31,32$

The concept of 'outside-to-inside' cellular cross-talk as the mechanism of atherosclerosis might be consistent with our observations and conclusion. ${ }^{12,34}$ Although the standard concept for atherogenesis progression is considered to be an 'inside-to-outside' theory, in which vascular inflammation and atherogenesis develop from the luminal surface, the 'outside-to-inside' hypothesis raises the possibility of the adventitia as the origin of vascular inflammation and atherogenesis. In early atherosclerotic lesions, increased adventitial vasa vasorum neovascularization and macrophages are seen before plaque neovascularization. These findings indicate that endothelial dysfunction is preceded by development of the vasa vasorum, creating a conduit for inflammatory cell transport to promote chronic inflammation and plaque neovascularization. ${ }^{35-37}$ Moreover, inflammatory cells directly infiltrate occlusive lesions from the vasa vasorum, which is a borderless area adjacent to EAT. ${ }^{38}$ Increased EAT might function as an inflammatory organ and contribute to the progression of CAD in all stages by facilitating chronic inflammation and thrombogenesis in 
epicardial coronary arteries.

\section{Study Limitations}

First, the present findings do not prove a direct link between increased epicardial fat volume and the development of atherosclerosis. Although increased VEAT could be a marker of severe atheromatosis and also be a risk factor for coronary total occlusions, the possible causative effect of epicardial fat accumulation has not been clarified. Qualitative analysis of epicardial fat using biochemical techniques will be required to confirm the effect of accumulated epicardial fat on the progression of coronary atherosclerosis. Second, the number of study participants was limited. The statistical power thus might be inadequate for any negative data. Third, we collected data from patients with a highrisk of CAD, who underwent coronary angiography. Thus, further investigation will be required to examine whether VEAT can be a predictor of CAD in a general population.

\section{Conclusions}

Excessive EAT was shown to be associated with proatherosclerotic risk factors and the development of atheromatosis and total occlusions of coronary arteries. Increased EAT might have a critical role in the occurrence of ACS and the subsequent formation of total occlusions.

\section{Acknowledgments}

This work was supported, in part, by the Medical School Faculty and an Alumni Grant from Keio University Medical Science Fund (T.A.).

\section{Disclosure}

There are no conflicts of interest in this study.

\section{References}

1. Yusuf S, Hawken S, Ounpuu S, Bautista L, Franzosi MG, Commerford $\mathrm{P}$, et al. Obesity and the risk of myocardial infarction in 27,000 participants from 52 countries: A case-control study. Lancet 2005; 366: $1640-1649$.

2. Carr DB, Utzschneider KM, Hull RL, Kodama K, Retzlaff BM, Brunzell JD, et al. Intra-abdominal fat is a major determinant of the National Cholesterol Education Program Adult Treatment Panel III criteria for the metabolic syndrome. Diabetes 2004; 53: 2087-2094.

3. Rexrode KM, Carey VJ, Hennekens CH, Walters EE, Colditz GA, Stampfer MJ, et al. Abdominal adiposity and coronary heart disease in women. JAMA 1998; 280: $1843-1848$.

4. Rexrode KM, Buring JE, Manson JE. Abdominal and total adiposity and risk of coronary heart disease in men. Int J Obes Relat Metab Disord 2001; 25: 1047-1056.

5. Fox CS, Massaro JM, Hoffmann U, Pou KM, Maurovich-Horvat P, Liu CY, et al. Abdominal visceral and subcutaneous adipose tissue compartments: Association with metabolic risk factors in the Framingham Heart Study. Circulation 2007; 116: 39-48.

6. Libby P, Ridker PM, Maseri A. Inflammation and atherosclerosis. Circulation 2002; 105: 1135-1143.

7. Sacks HS, Fain JN. Human epicardial adipose tissue: A review. Am Heart J 2007; 153: 907-917.

8. Iacobellis G, Ribaudo MC, Assael F, Vecci E, Tiberti C, Zappaterreno A, et al. Echocardiographic epicardial adipose tissue is related to anthropometric and clinical parameters of metabolic syndrome: A new indicator of cardiovascular risk. J Clin Endocrinol Metab 2003; 88: $5163-5168$

9. Mazurek T, Zhang L, Zalewski A, Mannion JD, Diehl JT, Arafat H, et al. Human epicardial adipose tissue is a source of inflammatory mediators. Circulation 2003; 108: 2460-2466.

10. Iacobellis G, Pistilli D, Gucciardo M, Leonetti F, Miraldi F, Brancaccio G, et al. Adiponectin expression in human epicardial adipose tissue in vivo is lower in patients with coronary artery disease. Cytokine 2005; 29: 251-255.

11. Baker AR, Silva NF, Quinn DW, Harte AL, Pagano D, Bonser RS, et al. Human epicardial adipose tissue expresses a pathogenic profile of adipocytokines in patients with cardiovascular disease. Cardiovasc Diabetol 2006; 5: 1.

12. de Vos AM, Prokop M, Roos CJ, Meijs MF, van der Schouw YT, Rutten A, et al. Peri-coronary epicardial adipose tissue is related to cardiovascular risk factors and coronary artery calcification in postmenopausal women. Eur Heart J 2008; 29: 777-783.

13. Gorter PM, van Lindert AS, de Vos AM, Meijs MF, van der Graaf Y, Doevendans PA, et al. Quantification of epicardial and peri-coronary fat using cardiac computed tomography; reproducibility and relation with obesity and metabolic syndrome in patients suspected of coronary artery disease. Atherosclerosis 2007; 197: 896-903.

14. Achenbach S, Moselewski F, Ropers D, Ferencik M, Hoffmann U, MacNeill B, et al. Detection of calcified and noncalcified coronary atherosclerotic plaque by contrast-enhanced, submillimeter multidetector spiral computed tomography: A segment-based comparison with intravascular ultrasound. Circulation 2004; 109: 14-17.

15. Hara T, Yamada S, Hayashi T, Ikeda Y, Yamashiro K, Mizutani K, et al. Accuracy of nonstenotic coronary atherosclerosis assessment by multi-detector computed tomography. Circ J 2007; 71: 911-914.

16. Achenbach S, Ropers D, Hoffmann U, MacNeill B, Baum U, Pohle $\mathrm{K}$, et al. Assessment of coronary remodeling in stenotic and nonstenotic coronary atherosclerotic lesions by multidetector spiral computed tomography. J Am Coll Cardiol 2004; 43: 842-847.

17. Ueno K, Anzai T, Jinzaki M, Yamada M, Kohno T, Kawamura A, et al. Diagnostic capacity of 64-slice multidetector computed tomography for acute coronary syndrome in patients presenting with acute chest pain. Cardiology 2008; 112: 211-218.

18. Jinzaki M, Yamada M, Sato K, Tanami Y, Anzai T, Sasaki K, et al. Overview image of the lumen and vessel wall in coronary CT angiography. Circ J 2008; 72: 671-673.

19. Jinzaki M, Sato K, Tanami Y, Yamada M, Anzai T, Kawamura A, et al. Diagnostic accuracy of angiographic view image for the detection of coronary artery stenoses by 64-detector row CT. Circ J 2009; 73: 691-698.

20. Van Mieghem CA, McFadden EP, de Feyter PJ, Bruining N, Schaar JA, Mollet NR, et al. Noninvasive detection of subclinical coronary atherosclerosis coupled with assessment of changes in plaque characteristics using novel invasive imaging modalities: The Integrated Biomarker and Imaging Study (IBIS). J Am Coll Cardiol 2006; 47: $1134-1142$.

21. Matsumoto N, Sato Y, Yoda S, Nakano Y, Kunimasa T, Matsuo S, et al. Prognostic value of non-obstructive CT low-dense coronary artery plaques detected by multislice computed tomography. Circ J 2007; 71: $1898-1903$.

22. Gensini GG. A more meaningful scoring system for determining the severity of coronary heart disease. Am J Cardiol 1983; 51: 606.

23. Hamsten A, Walldius G, Szamosi A, Dahlen G, de Faire U. Relationship of angiographically defined coronary artery disease to serum lipoproteins and apolipoproteins in young survivors of myocardial infarction. Circulation 1986; 73: 1097-1110.

24. Iacobellis G, Assael F, Ribaudo MC, Zappaterreno A, Alessi G, Di Mario U, et al. Epicardial fat from echocardiography: A new method for visceral adipose tissue prediction. Obes Res 2003; 11: 304-310.

25. Iacobellis G, Sharma AM. Epicardial adipose tissue as new cardiometabolic risk marker and potential therapeutic target in the metabolic syndrome. Curr Pharm Des 2007; 13: 2180-2184.

26. Thalmann S, Meier CA. Local adipose tissue depots as cardiovascular risk factors. Cardiovasc Res 2007; 75: 690-701.

27. Falk E, Shah PK, Fuster V. Coronary plaque disruption. Circulation 1995; 92: 657-671.

28. von Birgelen C, Hartmann M, Mintz GS, van Houwelingen KG, Deppermann N, Schmermund A, et al. Relationship between cardiovascular risk as predicted by established risk scores versus plaque progression as measured by serial intravascular ultrasound in left main coronary arteries. Circulation 2004; 110: 1579-1585.

29. Leber AW, Knez A, von Ziegler F, Becker A, Nikolaou K, Paul S, et al. Quantification of obstructive and nonobstructive coronary lesions by 64-slice computed tomography: A comparative study with quantitative coronary angiography and intravascular ultrasound. $J$ Am Coll Cardiol 2005; 46: 147-154.

30. Kandzari DE. The challenges of chronic total coronary occlusions: An old problem in a new perspective. J Interv Cardiol 2004; 17: 259-267.

31. Croce K, Libby P. Intertwining of thrombosis and inflammation in atherosclerosis. Curr Opin Hematol 2007; 14: 55-61.

32. Libby P. Current concepts of the pathogenesis of the acute coronary syndromes. Circulation 2001; 104: 365-372.

33. Hackett D, Davies G, Chierchia S, Maseri A. Intermittent coronary occlusion in acute myocardial infarction: Value of combined thrombolytic and vasodilator therapy. N Engl J Med 1987; 317: 1055- 
1059.

34. Chaowalit N, Lopez-Jimenez F. Epicardial adipose tissue: Friendly companion or hazardous neighbour for adjacent coronary arteries? Eur Heart J 2008; 29: 695-697.

35. Gossl M, Versari D, Mannheim D, Ritman EL, Lerman LO, Lerman A. Increased spatial vasa vasorum density in the proximal LAD in hypercholesterolemia--implications for vulnerable plaque-development. Atherosclerosis 2007; 192: 246-252.

36. Herrmann J, Lerman LO, Rodriguez-Porcel M, Holmes DR Jr, Richardson DM, Ritman EL, et al. Coronary vasa vasorum neovascularization precedes epicardial endothelial dysfunction in experi- mental hypercholesterolemia. Cardiovasc Res 2001; 51: 762-766.

37. Moulton KS, Vakili K, Zurakowski D, Soliman M, Butterfield C, Sylvin E, et al. Inhibition of plaque neovascularization reduces macrophage accumulation and progression of advanced atherosclerosis. Proc Natl Acad Sci USA 2003; 100: 4736-4741.

38. Srivatsa SS, Edwards WD, Boos CM, Grill DE, Sangiorgi GM, Garratt KN, et al. Histologic correlates of angiographic chronic total coronary artery occlusions: Influence of occlusion duration on neovascular channel patterns and intimal plaque composition. J Am Coll Cardiol 1997; 29: 955-963. 